\title{
Decrease Corneal Hysteresis in Early Glaucoma Patients Measured with Ocular Response Analyzer (ORA) Helps in Early Diagnosis of Glaucoma
}

\author{
Małgorzata Mulak ${ }^{1,2}$, Dorota Szumny ${ }^{2,3 *}$, Wojciech Czak ${ }^{1,2}$, Małgorzata Mimier ${ }^{1,2}$, Henryk Bujak ${ }^{4}$, Marta Misiuk- \\ $\mathrm{Hojło}^{1,2}$
}

${ }^{1}$ Katedra i Klinika Okulistyki Uniwersytetu Medycznego we Wrocławiu, Wrocław, Poland

${ }^{2}$ Klinika Okulistyki, Uniwersytecki Szpital Kliniczny we Wrocławiu, Wrocław, Poland

${ }^{3}$ Katedra i Zakład Farmakologii Uniwersytetu Medycznego we Wrocławiu, Wrocław, Poland

${ }^{4}$ Katedra Genetyki, Hodowli Roślin i Nasiennictwa, Uniwersytet Przyrodniczy we Wrocławiu, Wrocław, Poland

Submission: March 18, 2019; Published: April 17, 2019

*Corresponding author: Dorota Szumny, Katedra i Zakład Farmakologii AM we Wrocławiu ul. Mikulicza-Radeckiego 2, Wrocław, Poland

Abstract

The aim of the research was to compare the intraocular pressure value (IOP) measured with a GAT (Goldmann tonometer) with the cornea compensated IOP obtained with an ORA tonometer, and to establish whether there is a correlation between the IOP, corneal hysteresis and OCT RNFL results. Patients were divided into two groups: healthy individuals, with no ophthalmic history, and patients with early primary open angle glaucoma, treated pharmacologically with no history of either laser nor surgical eye treatment. The inclusion criteria were assessed based on the ophthalmic assessment of the optic nerve disc and perimetry (MD>-6dB). The control group included 25 subjects and the patient group 46 . All measurements were performed in the Glaucoma Outpatient Clinic of the Wroclaw University Hospital: intraocular pressure with GAT and ORA, central corneal thickness, OCT RNFL.

A significant positive correlation between ORA IOP and GAT IOP was found in the glaucoma group. There was significant negative correlation between ORA IOP and CH. There was a strong positive correlation between ORA IOP and GAT IOP results in the control group. Corneal hysteresis $(\mathrm{CH})$ in patients with early stage glaucoma, confirmed by incorrect OCT RNFL values, is lower compared with the control group. CH is an important parameter useful for glaucoma diagnosis and evaluation of risk groups. IOP values measured with the ORA tonometer correlated with results obtained with the GAT. ORA tonometry is a novel, noninvasive method of intraocular pressure and corneal hysteresis measurement, that can be used alternatively for GAT.

Keywords: Glaucoma; Diagnosis; Goldman aplanation tonometry; Ocular response analyzer; Corneal hysteresis

Abbrevations: ORA: Ocular Response Analyzer; IOP: Intraocular Pressure Value; GAT: Goldmann Tonometer; CH: Corneal Hysteresis; OCT RNFL: Optical Coherence Tomography Retinal Nerve Fiber Layer thickness; CCT: Central Corneal Thickness; CRF: Corneal Resistance Factor; NTG: Normal Tension Glaucoma; MD: Mean Deviation; PSD: Pattern Standard Deviation; GHT: Glaucoma Hemifield Test; SITA: Swedish Interactive Testing Algorithm; HRT: Heidelbert Retina Tomography

\section{Introduction}

Despite development of new diagnostic tools, the diagnosis and follow-up of glaucoma patients still remains a challenge in some cases. Imaging techniques widely used in the management of glaucoma patients such as Optical Coherence Tomography Retinal Nerve Fiber Layer thickness (OCT RNFL) and Heidelbert Retina Tomography (HRT) do not always allow precise diagnosis. On the other hand, perimetry - a test reflecting functional visual loss - is associated with higher subjectivity resulting from patient's attributes. Tonometry remains a vital examination for diagnosis and follow-up of glaucoma patients, because elevated intraocular pressure (IOP) is the only confirmed modifiable risk factor of glaucomatous neuropathy. However, IOP is a variable parameter that depends on time of the day, patient's posture or hydration status. Goldmann applanation tonometry (GAT) is widely accepted as a gold standard method for IOP measurement. It enables assessment of IOP based on the applanation force needed to flatten the cornea. GAT carries a high risk of error associated not only with the central corneal thickness (CCT), but also with general corneal properties, including its viscosity and elasticity. The result varies with amount of fluorescein used for the GAT measurement - an excess of fluorescein elevates the result, and - accordingly - insufficient amount lowers it $[1,2]$.

Tonometry is an area of intensive scientific research. New measurement techniques are being developed, aiming at exact IOP measurement, enabling more precise diagnosis and prognosis of glaucomatous neuropathy compared to other data [1,3-8]. 
The Reichert's ocular response analyzer (ORA) is a non-contact method that uses a bi-directional corneal applanation to determine the IOP. The main advantage of the device is its ability to acquire information about cornea's condition, defined as corneal hysteresis. Hysteresis of the cornea is calculated as a difference between results of first and second air-applanations. The aforementioned tonometer allows measurement of the corneal resistance factor (CRF) and Keratoconus Match Index that serve as tools for estimation of probability of development of keratoconus. The cornea compensated IOP (IOPcc) is a result obtained with the ORA tonometer adjusted for corneal properties. Another feature of the device is, so-called, Goldmann correlated IOP (IOPg) that is a tool estimating the IOP value that could be obtained with GAT $[1,3,7,8]$. In literature, corneal hysteresis is a property that allows establishment of the diagnosis of glaucoma. It could hypothetically serve as a tool for identification of glaucomatous neuropathy, particularly in unclear cases, and for stratification of risk groups.

The purpose of the research was to compare IOP measured with GAT and the IOPcc value obtained with the ORA tonometer, and to check whether a correlation exists between IOP, corneal hysteresis and OCT RNFL results. Patients were divided into two subgroups - the group 1 consisted of healthy individuals, with no ophthalmic history, and the group 2 included patients with early primary open angle glaucoma, treated pharmacologically. Patients qualified to the group 2 had no history of either laser or surgical eye treatment. Inclusion criteria were assessed based on the ophthalmic assessment of the optic nerve disc and on perimetry (MD >-6dB in Hodapp classification). The control group included 25 subjects - 22 women aged 27-84 years (the average age 53.9 years) and 3 men 19-71 y.o. (the average age: 43.3 years). The second group consisted of 46 patients, including 27 women aged 48-88 (the average age: 72.1 years), and 19 men aged 24-81 (the average age: 60.2 years).

All measurements were performed in the Glaucoma Outpatient Clinic of the Wroclaw University Hospital. All patients gave their informed consent for the participation in the study. Secondary analyses of suitably anonymised datasets do not require the approval of a local ethics committee. The average IOP obtained with ORA in the control group was $16.16 \mathrm{mmHg}$ (range; $9.2 \mathrm{mmHg}-23.6 \mathrm{mmHg}$ ). The average IOP value in the experimental group was $17.75 \mathrm{mmHg}$ (range: 8.6 - $31.7 \mathrm{mmHg}$ ). The statistical analysis of values in 2 subgroups using the t-Student test indicated a significant difference between these values. The average IOP in the control group was significantly lower than in the experimental group (16.16 $\mathrm{mmHg}$ vs. $17.75 \mathrm{mmHg}$ ). The $\mathrm{CH}$ average value in the control group was 11.10 (range: $7.1-14.8$ ), whereas for the experimental group the average value was 9.7 (range: 5.8 - 21.7). The comparison of values using the t-Student test indicated that $\mathrm{CH}$ was significantly lower in the control group compared to the experimental one.

Table 1: basic statistical data for control group.

\begin{tabular}{|c|c|c|c|c|c|}
\hline \multicolumn{6}{|c|}{ Descriptions } \\
\hline Variable & $\mathbf{N}$ & Average & Minimum & Maximum & Standard deviation \\
\hline ORA & 48 & 16,16 & 9,2 & 23,6 & 3,92 \\
\hline $\mathrm{CH}$ & 48 & 11,10 & 7,1 & 14,8 & 1,30 \\
\hline CCT & 48 & 561,60 & 476,0 & 637,0 & 30,78 \\
\hline GAT & 48 & 15,60 & 10,0 & 23,0 & 2,88 \\
\hline RNLF & 48 & 92,36 & 66,0 & 122,0 & 11,67 \\
\hline Patients age & 24 & 53,2 & 19 & 84 & \\
\hline Females & 21 & 53,9 & 27 & 84 & \\
\hline Males & 3 & 43,3 & 19 & 71 & \\
\hline
\end{tabular}

Table 2: basic statistical data for glaucomatous group..

\begin{tabular}{|c|c|c|c|c|c|}
\hline \multicolumn{6}{|c|}{ Descriptions } \\
\hline Variable & $\mathbf{N}$ & Average & Minimum & Maximum & Standard deviation \\
\hline ORA & 90 & 17,75 & 8,6 & 31,7 & 4,75 \\
\hline $\mathrm{CH}$ & 90 & 9,70 & 5,8 & 21,7 & 1,75 \\
\hline CCT & 90 & 553,33 & 470 & 665 & 36,82 \\
\hline GAT & 90 & 16,46 & 8,0 & 32,0 & 4,65 \\
\hline RNLF & 90 & 83,33 & 45,0 & 152,0 & 18,40 \\
\hline Patients age & 46 & 67,2 & 24 & 88 & \\
\hline Females & 27 & 72,1 & 48 & 88 & \\
\hline Males & 19 & 60,2 & 24 & 81 & \\
\hline
\end{tabular}

The average CCT in the control group was $561.6 \mu \mathrm{m}$ (range: $476 \mu \mathrm{m}-637 \mu \mathrm{m}$ ), while for the experimental group the aver-

age value was $533.33 \mu \mathrm{m}$ (range: $470 \mu \mathrm{m}-665 \mu \mathrm{m}$ ). The t-Student test didn't indicate any statistically significant differences 
between CCT in these two groups. The average GAT IOP for the control group was $15.6 \mathrm{mmHg}$ (range: $10 \mathrm{mmHg}-23 \mathrm{mmHg}$ ), while for the experimental group the average value was 16.46 mmHg (range: $8 \mathrm{mmHg}-32 \mathrm{mmHg}$ ). There was no statistically significant difference between the two groups. The average thickness of RNFL for the control group was $92.36 \mu \mathrm{m}$ (range: $66 \mu \mathrm{m}-122 \mu \mathrm{m}$ ), while for experimental group the average val-

Table 3: comparison of examined parameters.

\begin{tabular}{|c|c|c|c|c|c|}
\hline \multicolumn{7}{|c|}{ T-test } \\
\hline Variable & Average & Average & Minimum & Maximum & Standard deviation \\
\hline Control & Average & 16,16 & 9,2 & 23,6 & 3,92 \\
\hline Glaucoma & $\mathrm{t}$ & $\mathrm{df}$ & $\mathrm{p}$ & 14,8 & 1,30 \\
\hline ORA & 16,16 & 17,75 & $1,980^{*}$ & 136 & 0,0497 \\
\hline CH & 11,10 & 9,70 & $-4,873^{*}$ & 136 & 0,0001 \\
\hline CCT & 561,60 & 553,33 & $-1,318$ & 136 & 0,1898 \\
\hline GAT & 15,60 & 16,46 & 1,158 & 136 & 0,2488 \\
\hline RNLF & 92,36 & 83,33 & $-2,862^{*}$ & 136 & 0,0050 \\
\hline
\end{tabular}

${ }^{*} p<0,050$ was considered significant

Table 4: correlation coefficients matrix between parameters for control group.

\begin{tabular}{|c|c|c|c|c|c|}
\hline \multicolumn{7}{|c|}{ Correlation coefficients } & GAT & RNLF \\
\hline Variable & ORA & CH & CCT & $0,616^{*}$ & $-0,168$ \\
\hline ORA & 1,000 & $-0,176$ & 0,239 & 0,280 & $-0,001$ \\
\hline CH & $-0,176$ & 1,000 & $-0,017$ & 0,155 & $-0,030$ \\
\hline CCT & 0,239 & $-0,017$ & 1,000 & 1,000 & $-0,293$ \\
\hline GAT & $0,616^{*}$ & 0,280 & 0,155 & $-0,293$ & 1,000 \\
\hline RNLF & $-0,168$ & $-0,001$ & $-0,030$ & & \\
\hline
\end{tabular}

${ }^{*} p<0,050$ was considered significant

The glaucoma group demonstrated a significant positive correlation between the ORA IOP and the GAT IOP. There was a significant negative correlation between ORA IOP and CH. No

Table 5: correlation coefficients matrix between parameters for glaucomatous group.

\begin{tabular}{|c|c|c|c|c|c|c|}
\hline \multicolumn{7}{|c|}{ Correlation coefficients } \\
\hline Variable & ORA & CH & CCT & GAT & RNLF & Disease duration \\
\hline ORA & 1,000 & $-0,374^{*}$ & 0,181 & $0,760^{*}$ & $-0,139$ & 0,066 \\
\hline CH & $-0,374^{*}$ & 1,000 & 0,200 & $-0,128$ & 0,099 & 0,079 \\
\hline CCT & 0,181 & 0,200 & 1,000 & 0,183 & $-0,008$ & $-0,136$ \\
\hline GAT & $0,760^{*}$ & $-0,128$ & 0,183 & 1,000 & $-0,042$ & $0,242^{*}$ \\
\hline RNLF & $-0,139$ & 0,099 & $-0,008$ & $-0,042$ & 1,000 & 0,218 \\
\hline $\begin{array}{c}\text { Disease } \\
\text { duration }\end{array}$ & 0,066 & 0,079 & $-0,136$ & $0,243^{*}$ & 0,218 & 1,000 \\
\hline
\end{tabular}

${ }^{*} p<0,050$ was considered significant

\section{Discussion}

IOP values measured with the ORA were significantly higher in the experimental (glaucomatous) group than in the control one. There was a statistically significant positive correlation between the ORA IOP and the GAT IOP. Results of CH and RNFL thickness were significantly lower in the glaucoma group compared to the control. Results obtained in our research are in accordance with results obtained in previous studies. Experimental statistically significant correlation was found between other parameters (Table 5). 
jects were divided into 4 subgroups based on the advancement of glaucomatous neuropathy. Main parameters analyzed were: progression of visual field MD dependent on IOP values, $\mathrm{CH}$, and CRF. IOP was measured with the GAT and the ORA as IOPcc and IOPg. Perimetry was assessed using the Humphrey device, based on parameters such as mean deviation (MD), pattern standard deviation (PSD) and glaucoma hemifield test (GHT).

The statistical analysis in two subgroups with fast and slow glaucomatous neuropathy progression indicated a faster progression in subjects with a low corneal hysteresis. Fast progressors had corneal hysteresis of $8.4 \mathrm{mmHg}(+/-1 \mathrm{mmHg})$, while slow progressors had $\mathrm{CH}$ of $9.3 \mathrm{mmHg}(+/-1 \mathrm{mmHg})$. The difference was statistically significant. IOP measured with the GAT and with the ORA, as IOPCC and IOPg, was significantly higher among fast progressors. In both subgroups, the IOP value measured with the GAT was significantly lower when than that measured with the ORA tonometer. The difference between IOPcc and GAT was $3.8 \mathrm{mmHg}$ in the fast progressors subgroup, while for slow progressors the difference was smaller $-1.9 \mathrm{mmHg}$. There was no significant difference in CCT between groups. The research indicated that a faster progression of perimetric deficits was measured among NTG patients with a low $\mathrm{CH}$ and a high IOPcc value, particularly when the difference between IOPcc and GAT was higher. Results presented by authors indicated that $\mathrm{CH}$ might serve as a diagnostic tool. On the other hand, the results indicated that underestimation of IOP values using the GAT compared to ORA results might entail a change in diagnosis from NTG to POAG.

Congton et al. [9] conducted a research on 230 patients with POAG and suspected glaucoma. Analyzed parameters included a correlation between CCT and $\mathrm{CH}$ compared to $\mathrm{ONH}$ parameters (c/d ratio - CDR) and perimetry. Perimetric parameters including MD, PSD and GHT were analyzed. There was a statistically significant correlation between the increase of CDR and lower CCT values. The risk of progression was higher among older patients, with long treatment time and lower values of $\mathrm{CH}$. There was no correlation between visual field changes and a decrease of CCT. A multivariate analysis revealed that axial length of the eye constituted a significant risk factor of progression of glaucomatous neuropathy, but after implementation of the parameter, the role of $\mathrm{CH}$ decreased, which suggests that both parameters seem to increase the risk of glaucomatous neuropathy in a similar manner. $70 \%$ of the patients in the study were Caucasian, $18.7 \%$ were Afro-American patients. Afro-American patients tended to have slightly thinner CCT (approximately $20 \mu \mathrm{m}$ ) as compared to Caucasian patients and a higher predilection for elevation of CDR in the course of the study. Although neither CCT nor $\mathrm{CH}$ correlated significantly with MD nor PSD, the mean MD was lower among Afro-American subjects.

Streho, et al. [10] came to the similar conclusions comparing intraocular pressure values obtained with the ORA tonometer (cornea compensated IOP - IOPcc and Goldmann correlated IOP - IOPg), the Goldmann tonometer and a non-contact tonometer
(IOPair). Features of the cornea defined as a corneal hysteresis $(\mathrm{CH})$ and a central corneal thickness, measured using ultrasound pachymetry, were analyzed additionally. Three groups of patients were included in the study - glaucomatous patients (67 eyes), patients with ocular hypertension (55 eyes) and the control group of healthy individuals (207 eyes). The statistical analysis showed a correlation between IOP results obtained using four different methods (Goldmann IOP, IOPair, IOPg, IOPcc) in all three groups of patients. Averaged $\mathrm{CH}$ was the lowest in the group with ocular hypertension $(9.6 \mathrm{mmHg})$, slightly higher in glaucomatous patients ( $9.8 \mathrm{mmHg}$ ) and the highest in the control group (10.3 mmHg). There were no differences in $\mathrm{CH}$ among three groups regarding age, but there was a correlation between $\mathrm{CH}$ and CCT values. A relationship between $\mathrm{CH}$ and the cornea compensated IOP (IOPcc) was shown - an elevation in IOPcc was associated with a decrease in $\mathrm{CH}$. Calculations suggest that the analysis of condition of the cornea may be useful in both diagnostics and monitoring of glaucoma.

A decrease in corneal hysteresis $(\mathrm{CH})$ and reduction of the corneal resistance factor (CRF) were demonstrated by Pillunat, et al. [11] in glaucomatous patients. The difference between the group with ocular hypertension and the control group was statistically significant. There was a correlation between cornea's biochemical parameters and IOP, CCT, axial length and patient's age. The lowest $\mathrm{CH}$ and $\mathrm{CRF}$ values were observed in patients with the most advanced changes in the visual field. The author claimed that a decline in cornea's biochemical parameters was probably associated with more advanced glaucomatous changes and those patients should be treated more aggressively and be more frequently monitored.

Majority of studies investigating $\mathrm{CH}$ in glaucomatous patients, or with suspected glaucoma, compare $\mathrm{CH}$ with IOP, whereas only few of them correlate $\mathrm{CH}$ with the retinal nerve fiber layer thickness. Wells [12] published results of the prospective study on 100 patients ( 38 with glaucoma, 62 healthy individuals). The spherical equivalent, the axial length of eyeball, IOP measured with the Goldmann and Pascal tonometer, the ocular pulse amplitude, CCT and CH were analyzed. With use of a modified ring, used for LASIK procedures, IOP in the right eye was elevated up to $64 \mathrm{mmHg}$ for less than 30 seconds. Before and after the IOP increase, the surface of the optic nerve was mapped using HRT II. The optic nerve cup was analyzed during the IOP elevation and correlated with examined parameters. $\mathrm{CH}$ as well as CCT were lower in the glaucomatous group than in the control one, and $\mathrm{CH}$ correlated with an average increase in the cup size.

One of the studies focusing on the correlation between $\mathrm{CH}$ and parameters of glaucomatous damage was published by $\mathrm{VU}$ Dm [13]. In 131 patients with suspected glaucoma, S-OCT and CH were performed using the Ocular Response Analyzer Reichert. The Pearson's statistical analysis showed a significant correlation between $\mathrm{CH}$ and the mean defect. $\mathrm{CH}$ was more strongly associated with visual field parameters than with damage markers, such as RNFL thickness measured using SD-OCT [13]. 
Mansouri, et al. [14] examined 191 patients with suspected or diagnosed glaucoma and measured: $\mathrm{CH}$ and CRF using the Ocular Response Analyzer Reichert, visual field using the Swedish interactive testing algorithm (SITA), RNFL thickness using GDx and SD-OCT. The final analysis showed correlation between $\mathrm{CH}$, $\mathrm{CRF}$ and MD parameter in the visual field test. A poor correlation between $\mathrm{CH}, \mathrm{CRF}$ and averaged RNFL thickness, measured by GDx, was demonstrated in 204 eyes. There was no correlation between corneal parameters and RNFL measured with the OCT in 146 eyes. When CCT, age and axial eyeball length were considered in the analysis, the correlation between $\mathrm{CH}, \mathrm{CRF}$ and RNFL was no longer statistically significant.

\section{Conclusion}

- The corneal hysteresis $(\mathrm{CH})$ in patients with early stage glaucoma, confirmed by incorrect OCT RNFL values, is lower than in the control group. $\mathrm{CH}$ is an important parameter that is useful in the diagnosis of glaucoma, and for extraction of risk groups.

- $\quad$ IOP values measured with the ORA tonometer correlate with results obtained with the Goldmann tonometer.

- $\quad$ ORA tonometry is a novel, noninvasive and accurate method of intraocular pressure and corneal hysteresis measurement, that can be used alternatively for the Goldmann tonometer. Due to the correlation between $\mathrm{CH}$ values and glaucomatous damage, ORA may be useful for diagnosis of glaucoma at early stage.

\section{Acknowledgement}

There was no support in the form of grants, equipment, drugs, etc. We declare that the article is original, has not been published before and is not currently being considered for publication elsewhere. All authors declare no conflict of interest. The manuscript has been read and approved by all the authors, each author believes that the manuscript represents honest work.

\section{References}

1) (2014) European Glaucoma Society: Terminology and guidelines for glaucoma. (2014) The fourth edition. Savona, Italy

2) Goldmann H, Schmidt $T$ (1957) Applanation tonometry. Ophthalmologica 134(4): 221-242.
3) Miszczyk J, Karwat Szwabowicz M, Taranek A, Szmuksta Ł, Chaniecki P (2015) Charakterystyka i współczesne metody pomiaru ciśnienia wewnątrzgałkowego. Magazyn Lekarza Okulisty 9 (6): 249-257.

4) Mulak M, Czak W, Grobarek B, Borwińska M, Misiuk Hojło M (2015) Pomiary ciśnienia wewnątrzgałkowego przy pomocy tonometru aplanacyjnego Goldmanna oraz tonometru rezonansowego- badania porównawcze. Magazyn Lek. Okulisty 9(3): 140-144.

5) Berk TA, Yang PT, Chan CC (2016) Prospective Comparative Analysis of 4 Different Intraocular Pressure Measurement Techniques and Their Effects on Pressure Readings. J Glaucoma 25(10): e897-e904.

6) Vandewalle E, Vandenbroeck S, Stalmans I, Zeyen T (2009) Comparison of Icare, dynamic contour tonometer and ocular response analyzer with Goldmann applanation tonometer in patients with glaucoma. Eur J Ophthalmol19(5): 783-789.

7) Hager A, Loge K, Schroeder B, Fullhas MO, Wiegand W (2008) Effect of central corneal thickness and corneal hysteresis on tonometry as measured by dynamic contour tonometry, ocular response analyser, and Goldmann tonometry on glaucomatosus eyes. J Glaucoma 17(5): 361-365.

8) Hong Y, Shoji N, Morita T, Hirasawa K, Matsumura K, et al. (2016) Comparison of corneal biomechanical properties in normal tension glaucoma patients with different visual field progression speed. Int J Ophthalmol 9(7): 973-978.

9) Congdon NG, Broman AT, Bandeen Roche K, Grover D, Quigley HA (2006) Central corneal thickness and corneal hysteresis associated with glaucoma damage. Am j Ophthalmol 141(5): 886-875.

10)Streho M, Dariel R, Giraud JM, Verret C, Fenolland JR, et al. (2008) Evaluation of the Ocular Response Analyzer in ocular hypertension, glaucoma and normal populations. Prospective study in 329 eyes. J Fr Ophthalmol 31(10): 953-960.

11)Pillunat KR, Hermann C, Spoerl E, Pillunat LE (2016) Analyzing biomechanical parameters of the cornea with severity open- angle glaucoma. Graefes Arch Clin Ophthalmol 254(7):1345-1351.

12)Wells AP1, Garway-Heath DF, Poostchi A, Wong T, Chan KC, et al. (2008) Corneal hysteresis but not corneal thickness correlates with optic nerve sufface compliance in glaucoma patients. Invest Ophthalmol Vis Sci 49 (8): 3262-3268.

13)Vu DM, Siva FQ Hoseltine SJ, Ehrlich JR, Radccliffe NM (2013) Relationship between corneal histeresis and optic nerve parametrs measured with spectral domain optical coherence tomography. Graefes Arch Clin Exp Ophthalmol 251 (7): 1777-1783.

14)Mansouri K, Leite MT, Weinreb RN, Tafreshi A, Zangwill LM, et al (2012) Association between corneal biomechanical properties and glaucoma severity. Am J Ophthalmol 153(3): 419-427. 
This work is licensed under Creative Commons Attribution 4.0 License DOI: 10.19080/CTBEB.2019.19.556004

\section{Your next submission with Juniper Publishers} will reach you the below assets

- Quality Editorial service

- Swift Peer Review

- Reprints availability

- E-prints Service

- Manuscript Podcast for convenient understanding

- Global attainment for your research

- Manuscript accessibility in different formats ( Pdf, E-pub, Full Text, Audio)

- Unceasing customer service

Track the below URL for one-step submission https://juniperpublishers.com/online-submission.php 